\title{
PRESYNAPTIC INHIBITORY EFFECT OF ACETYLCHOLINE IN THE HIPPOCAMPUS ${ }^{1}$
}

\author{
RITA J. VALENTINO AND RAYMOND DINGLEDINE
}

Department of Pharmacology, University of North Carolina School of Medicine, Chapel Hill, North Carolina 27514

\begin{abstract}
(1) In order to investigate the effects of acetylcholine (ACh) on synaptic transmission in the rat hippocampus, extracellular and intracellular recordings were made from pyramidal neurons in an in vitro slice preparation while synaptic inputs to the cell population were stimulated. ACh was applied ionophoretically into somatic and dendritic layers of the slice.

(2) ACh applied into the apical dendritic layer of the CA1 region reduced the size of the locally evoked field excitatory postsynaptic potential (EPSP) without altering the size of the afferent fiber volley. Likewise, dendritically applied ACh reduced the size of intracellularly recorded EPSPs. This effect of ACh appeared to be muscarinic since it was not affected by hexamethonium (up to $3 \times 10^{-5}$ M) but was antagonized by atropine in a dose-dependent manner.

(3) The distribution of ACh-sensitive sites matched closely the spatial distribution of activated synapses on the pyramidal cell dendrites as shown by ionophoretic mapping experiments.

(4) In contrast to the effects of dendritic applications of $\mathrm{ACh}$, ionophoresis of $\mathrm{ACh}$ into the cell layer resulted in an increase and prolongation of EPSPs and a transient decrease in the size of recurrent somatic inhibitory postsynaptic potentials (IPSPs). These effects on synaptic potentials could not be explained by the observed changes in membrane potential and input resistance following somatic application of ACh.

(5) Short dendritic applications of ACh had no consistent effect on the membrane potential or slope conductance of pyramidal neurons and did not attenuate the depolarization evoked by brief dendritic applications of glutamate. In addition, the time course of ACh-reduced EPSPs was not different from control.

(6) We conclude that ACh exerts a presynaptic inhibitory effect on both excitatory and inhibitory afferents to hippocampal pyramidal neurons. This effect of $\mathrm{ACh}$ is widespread, occurring in all regions of Ammon's horn tested as well as in stratum moleculare of fascia dentata.
\end{abstract}

Anatomical studies have identified a diffuse projection of fibers that originate in the medial septal nuclei and terminate in the hippocampus (Mosco et al., 1973; Mellgren and Srebro, 1973; Segal and Landis, 1974; Rose et al., 1976; Swanson, 1978). The cholinergic nature of this system is generally accepted (Lewis et al., 1967; Dudar, 1975). However, the physiolugical consequences of activating these inputs and the identity of their cellular targets are uncertain. Early ionophoretic studies demonstrated that application of acetylcholine (ACh) to both pyramidal and presumed basket cells results in an elevation of spontaneous firing rate that is blocked readily by atropine (Biscoe and Straughan, 1966; Bland et al., 1974; Bird and Aghajanian, 1975; Segal, 1978). Intracellular recordings reveal that ionophoretically applied ACh

This work was supported by National Institutes of Health Grants DA02360 and NS07166 and a Sloan Research Fellowship award to R. D.

${ }^{2}$ To whom correspondence should be addressed. produces depolarization and a slope conductance decrease of pyramidal cells (Kelly et al., 1979; Benardo and Prince, 1980; Dodd et al., 1981). However, surprisingly few reports have addressed the question of whether these excitatory responses mimic a physiological effect of septal afferents. In investigations in which the medial septal area has been stimulated electrically (Andersen et al., 1961a, b; Salmoiraghi and Stefanis, 1967; Alvarez-Leefmans and Gardner-Medwin, 1975; DeFrance et al., 1978), it has been difficult to block evoked responses convincingly with atropine. These findings suggest that the physiological actions of synaptically released ACh in the hippocampus may be more subtle than direct excitation of hippocampal neurons. Indeed, there is evidence for an additional action of $\mathrm{ACh}$ in the hippocampus. Perfusion of a dentate gyrus slice with $\mathrm{ACh}$ can abolish a synaptically evoked granule cell discharge (Yamamoto and Kawai, 1967), and later experimental evidence was consistent with a presynaptic inhibitory role for ACh (Hounsgaard, 1978a, b). 
In order to investigate cholinergic actions on synaptic transmission in the hippocampus, we have used extraand intracellular recording techniques to examine the effects on synaptic potentials produced by application of $\mathrm{ACh}$ into the various layers of the slice preparation. When applied into the region of activated synapses, $\mathrm{ACh}$, acting through muscarinic receptors, reduced the size of excitatory postsynaptic potentials (EPSPs) and inhibitory postsynaptic potentials (IPSPs), an effect that did not appear to be due to a direct action on pyramidal neurons. This inhibitory action of $\mathrm{ACh}$ is widespread, occurring on all major synaptic afferents to pyramidal cells of Ammon's horn and granule cells of the dentate gyrus. A preliminary account of some of these results has been published (Valentino and Dingledine, 1981).

\section{Materials and Methods}

Rat hippocampal slices were prepared and maintained as described by Dingledine et al. (1980). Briefly, rats weighing 125 to $200 \mathrm{gm}$ were anesthetized with ether and the hippocampus was dissected out. Nearly traverse slices, $400 \mu \mathrm{m}$ thick, were cut with a Sorvall tissue chopper and then transferred to a recording chamber by means of a wide bore glass tube and suction bulb. The slices were maintained at 32 to $37^{\circ} \mathrm{C}$ and superfused with artificial cerebrospinal fluid (ACSF) at a rate of 0.3 to 1 $\mathrm{ml} / \mathrm{min}$. The composition of the ACSF was (in millimolar concentrations): $\mathrm{NaCl}, 130 ; \mathrm{KCl}, 3.5 ; \mathrm{NaH}_{2} \mathrm{PO}_{4}, 1.25$; $\mathrm{NaHCO}_{3}, 24 ; \mathrm{CaCl}_{2} 2 \mathrm{H}_{2} \mathrm{O}, 1.5 ; \mathrm{MgSO}_{4} 7 \mathrm{H}_{2} \mathrm{O}, 1.5$; and glucose, 10. The solution was saturated with $95 \% \mathrm{O}_{2}, 5 \%$ $\mathrm{CO}_{2}$ to maintain a $\mathrm{pH}$ of 7.3 to 7.4. A humidified stream of warm $\mathrm{O}_{2} / \mathrm{CO}_{2}$ was directed over the upper surface of the slices. Recording was not attempted until at least 60 min had elapsed from the time that the slices were placed in the chamber. In experiments in which recurrent IPSPs were recorded, a razor blade chip was used to make a cut through the stratum (st.) oriens and st. pyramidale of each slice (nomenclature of Lorente de No, 1934), thereby isolating the alveus for more selective activation of the recurrent inhibitory pathway (Dingledine and Langmoen, 1980). Extracellular synaptic field potentials were recorded by glass micropipettes (10 to 40 megohms) filled with $3 \mathrm{M} \mathrm{NaCl}$, which were positioned under visual control and lowered to a depth of 100 to $150 \mu \mathrm{m}$. Intracellular recordings were made by fiber-filled glass micropipettes pulled on a Brown-Flaming type puller (David Kopf Instruments) and filled with $3 \mathrm{M}$ potassium acetate. The resistance of these electrodes, evaluated with square pulses, ranged from 100 to 200 megohms.

Sharpened tungsten cathodes positioned visually among the afferent fibers of the st. radiatum, or occasionally st. oriens, were used to stimulate orthodromically the pyramidal cells of the CA1 region with constant current negative square wave pulses (20 to $200 \mu \mathrm{A}, 0.1$ msec). The pyramidal cells of the CA1 region were stimulated antidromically by a tungsten electrode positioned in the alveus on the subicular side of the lesion. The effectiveness of the lesion for preventing contamination of recurrent IPSPs by EPSPs was tested by delivering a high intensity tetanizing stimulus $(\geq 100 \mu \mathrm{A}, 10 \mathrm{~Hz})$ through the electrode situated in the alveus. Only if this train evoked a pure antidromic population spike, with no evidence of a facilitating orthodromic population spike, was the slice used to record recurrent IPSPs.

Single barrel microionophoretic pipettes (20 to $80 \mathrm{meg}$ ohms) were filled with either acetylcholine chloride $(0.5$ M, pH 5.5) or monosodium l-glutamate (1 $\mathrm{M}, \mathrm{pH} 7.5$ ). Ejection and backing currents ranged between 10 to 200 and 0 to $5 \mathrm{nA}$, respectively. The ionophoretic pipettes were positioned visually by separate micromanipulators and lowered into the slice with hydraulic drives. Following each successful penetration, the depth of the glutamate, and often the ACh pipette, was readjusted to produce a large and short latency response. For antagonism experiments, the slices were perfused with ACSF containing either atropine sulfate, $10^{-8}$ or $10^{-7} \mathrm{M}$, or hexamethonium bromide, $3 \times 10^{-6}$ or $3 \times 10^{-5} \mathrm{M}$. All drugs were obtained from Sigma.

Recorded signals were led through negative capacitance DC-coupled electrometers. The intracellular electrometer had a bridge configuration that allowed current pulses to be passed across the cell membrane in order to change the membrane potential and monitor input resistance. When this was done, the bridge balance was checked routinely and adjusted if necessary (Engel et al., 1972). Signals were displayed on an oscilloscope and stored on magnetic tape. During intracellular recordings, a chart recorder was used to monitor membrane potential and ionophoretic currents. Recorded signals were averaged (Nicolet model 1072) before photography, and measurements were made from the film or chart by hand.

\section{Results}

Effect of ACh on synaptic field potentials. A recording electrode positioned "on-beam" in the layer of activated excitatory synapses in st. radiatum records a characteristic field potential in response to orthodromic stimulation (Fig. 1D). The evoked response consists of a sharp triphasic potential (arrow), which has been interpreted as an axonal spike or afferent fiber volley, followed by a slower negativity whose initial slope (the field EPSP) is considered proportional to postsynaptic current density (Andersen et al., 1978). The magnitude of the volley generated in the afferent fibers was proportional to the intensity of the orthodromic stimulus (Fig. $1 A$ ). Likewise, as long as moderate stimulus intensities were used, the field EPSP was a linear function of the magnitude of this volley (Fig. $1 B$ ). The effect of $\mathrm{ACh}$ on orthodromic activation of CA1 pyramidal neurons was examined by ionophoresing ACh into the somatic and dendritic regions of the slice.

When applied into the cell layer, ACh increased the size of evoked population spikes recorded extracellularly as expected from its slow depolarizing effect. However, when ACh was applied directly into the apical dendritic region of activated synapses, the evoked negative population spike recorded in the cell layer was reduced within a few seconds. This action of ACh was accompanied by a selective reduction of the dendritic field EPSP, while the presynaptic volley was unaffected (Fig. $1 D$, control, dashed line). Similarly, the slope of the synaptic inputoutput curve was decreased by ACh (Fig. $1 B$ ) although 
the relationship between orthodromic stimulus and presynaptic volley was unaffected (Fig. 1A). The mean decrease in the slope of the synaptic input-output curve produced by ACh was $43 \pm 3 \%$ in eight slices (Table I). Under our experimental conditions, this represented a near maximal inhibitory effect of $\mathrm{ACh}$. A similar reduction of the field EPSP by focal ionophoresis of ACh could be demonstrated in st. oriens of CA1, st. moleculare of the dentate gyrus, and st. radiatum of CA3, indicating the widespread nature of this inhibitory effect.

Pharmacology of the ACh effect. In order to determine whether the inhibitory effect of $\mathrm{ACh}$ described above
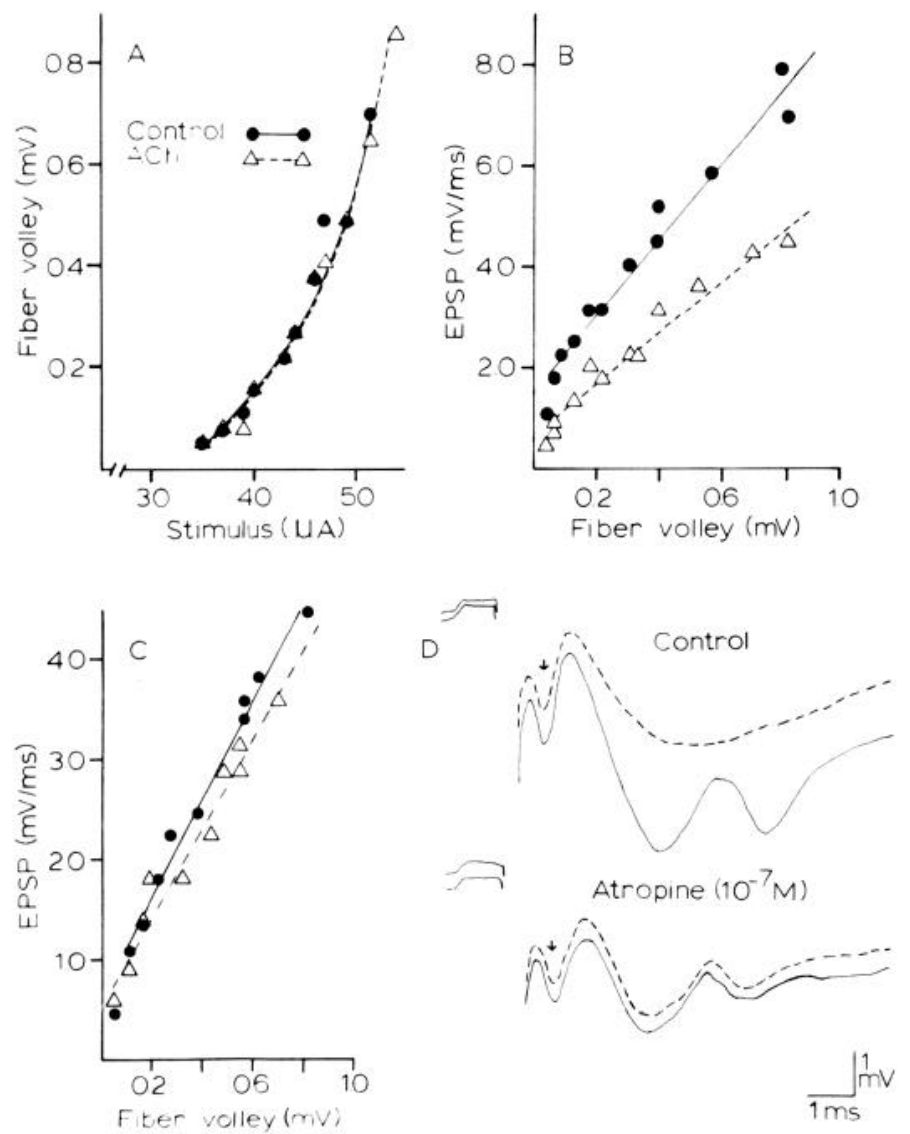

Figure 1. Depression by ACh of synaptic field potentials and antagonism by atropine. Recording and stimulating electrodes were positioned in st. radiatum of the CA1 region. Input-output curves were constructed by manually varying the stimulus intensity and plotting $(A)$ the size of the evoked afferent fiber volley as a function of stimulus current and $(B$ and $C$ ) the initial slope of the field EPSP as a function of fiber volley. In each graph, the solid circles represent responses obtained before, and triangles those immediately after, an ionophoretic application of ACh $(64 \mathrm{nA}$ for $6 \mathrm{sec})$ into st. radiatum near the recording electrode. Thus, each graph was built up from 10 to 12 separate $\mathrm{ACh}$ applications. Input-output curves were determined before $(A$ and $B)$ and 40 min after $(C)$ perfusing the slice with $10^{-7} \mathrm{M}$ atropine. $D$, Sample records, with each trace being the digital average of four sweeps. Solid lines show responses before, and dashed lines those immediately after, an $\mathrm{ACh}$ application. Arrows mark the peak of the fiber volley; the breaks in the records indicate stimulus artifacts. ACh reduced the field EPSP without affecting the size or shape of the afferent volley, and this effect was antagonized by $10^{-7} \mathrm{M}$ atropine.
TABLE I

Antimuscarinic reversal of ACh effect

\begin{tabular}{|c|c|c|c|c|c|}
\hline \multirow{3}{*}{$\begin{array}{l}\text { Experi- } \\
\text { ment }\end{array}$} & \multirow{3}{*}{$\begin{array}{c}\text { Percentage } \\
\text { of } \\
\text { Inhibition } \\
\text { by } \mathrm{ACh}^{a}\end{array}$} & \multicolumn{4}{|c|}{$\begin{array}{c}\text { Percentage of Control of ACh Effect }{ }^{b} \text { in } \\
\text { Presence of: }\end{array}$} \\
\hline & & \multicolumn{2}{|c|}{ Hexamethonium } & \multicolumn{2}{|c|}{ Atropine } \\
\hline & & $3 \times 10^{-6} \mathrm{M}$ & $3 \times 10^{-5} \mathrm{M}$ & $10^{-8} \mathrm{M}$ & $10^{-7} \mathrm{M}$ \\
\hline 1 & 44 & 108 & & 120 & 31 \\
\hline 2 & 40 & 95 & & 62 & 21 \\
\hline 3 & 41 & 74 & & 111 & 21 \\
\hline 4 & 31 & 140 & & & \\
\hline 5 & 44 & & & & 23 \\
\hline 6 & 61 & & 86 & & \\
\hline 7 & 46 & & 92 & 75 & 5 \\
\hline 8 & 33 & & & & 35 \\
\hline Mean $^{c}$ & $43 \pm 3$ & $104 \pm 16$ & 89 & $92 \pm 16$ & $23 \pm 5$ \\
\hline
\end{tabular}

${ }^{a}$ Percentage of decrease in the control slope of the input-output curve produced by ionophoretic application of $\mathrm{ACh}(60$ to $120 \mathrm{nA})$ for 6 to 10 sec.

${ }^{b}$ Percentage of the inhibition produced by $\mathrm{ACh}$ in the absence of the antagonist.

Mean of determinations \pm SEM.

was mediated by muscarinic or nicotinic receptor activation, periodic mid-apical dendritic application of $\mathrm{ACh}$ was carried out and field potentials were recorded while the slices were perfused with either hexamethonium or atropine.

Perfusion of the slices with ACSF-containing atropine, $10^{-7} \mathrm{M}$, markedly inhibited the effect of ACh upon the field EPSP (Fig. $1 D$ ). The antagonism by atropine also was shown by an attenuation of the $\mathrm{ACh}$-induced reduction of the slope of the synaptic input-output curve (Fig. $1 C$ ). This concentration of atropine reduced the effect of $\mathrm{ACh}$ in six slices by $77 \%$ (Table I). The effect of atropine was dose dependent since $10^{-8} \mathrm{M}$ atropine did not produce a significant reversal of the $\mathrm{ACh}$-induced inhibition (Table I). Perfusion of the slices with the nicotinic antagonist, hexamethonium $\left(3 \times 10^{-6}\right.$ or $\left.3 \times 10^{-5} \mathrm{M}\right)$, did not reduce the inhibitory effect of $\mathrm{ACh}$ significantly (Table I). Atropine $\left(10^{-7} \mathrm{M}\right)$, by itself, had no significant effect on either the size of the population spike or the slope of the synaptic input-output curve, which, in the presence of atropine, was $88 \%(\mathrm{SD}=28 \% ; n=11)$ of the control slope.

Localization of the ACh effect. In order to determine the spatial distribution of ACh-sensitive sites, ionophoretic mapping experiments were carried out in which the relative potency of $\mathrm{ACh}$ for reducing the field EPSP was measured as the ionophoretic pipette was moved along a line parallel to the dendritic axis of the pyramidal neurons. Distances between recording and ionophoretic pipettes were measured with an eyepiece micrometer to an accuracy of approximately $20 \mu \mathrm{m}$. The locations of the major visual landmarks of the slice (borders of alveus and cell layer, hippocampal fissure) within the micrometer field also were noted to facilitate later reconstruction of the recording and ionophoresis sites. In each experiment, the ionophoretic dose of $\mathrm{ACh}$ in nanocoulombs $(\mathrm{nC})$ required to reduce the size of an evoked field EPSP by a standard amount (approximately $30 \%$ ) was determined for 5 to 11 drug delivery sites. At the most sensitive 
sites, the ionophoretic current was adjusted in order to reach the criterion effect in 5 to $10 \mathrm{sec}$. At each site, the responses to two to six drug applications were averaged. In eight slices, apical dendritic delivery of ACh was more potent in reducing the field EPSP when the ionophoretic pipette was $150 \mu \mathrm{m}$ deep than when it was 50,100 , or 200 $\mu \mathrm{m}$ deep. Therefore, in mapping experiments, the depth of the ACh pipette was set $150 \mu \mathrm{m}$ below the slice surface.

Figure 2 illustrates the results of one experiment in which the spatial distribution of ACh-sensitive sites was compared to the distribution of active excitatory synapses. As shown in the schematic diagram in Figure 2, stimulating and recording electrodes were positioned in the mid-apical dendritic region, while the ACh pipette was placed sequentially at each of eight levels denoted by small black circles. As the ACh pipette was moved away from the recording electrode along a line parallel to the pyramidal dendritic axis, there was a progressive increase in the ionophoretic dose required to produce the same reduction in the EPSP (Fig. 2, solid circles). At the most sensitive site near the recording electrode, the criterion effect was reached with a dose of ACh of only $20 \mathrm{nC}(4 \mathrm{nA}$ for $5 \mathrm{sec}$ ), while $6600 \mathrm{nC}$ of $\mathrm{ACh}$ ( $153 \mathrm{nA}$ for $43 \mathrm{sec}$ ) were required to elicit the same response when the ionophoretic pipette was located $230 \mu \mathrm{m}$ distant. A similar decrement in $\mathrm{ACh}$ potency was produced regardless of whether the ionophoretic pipette was moved toward the cell layer or st. lacunosum moleculare. For comparison to the map of ACh sensitivity, the spatial distribution of activated excitatory synapses was estimated by measuring the amplitude of the fiber volley at

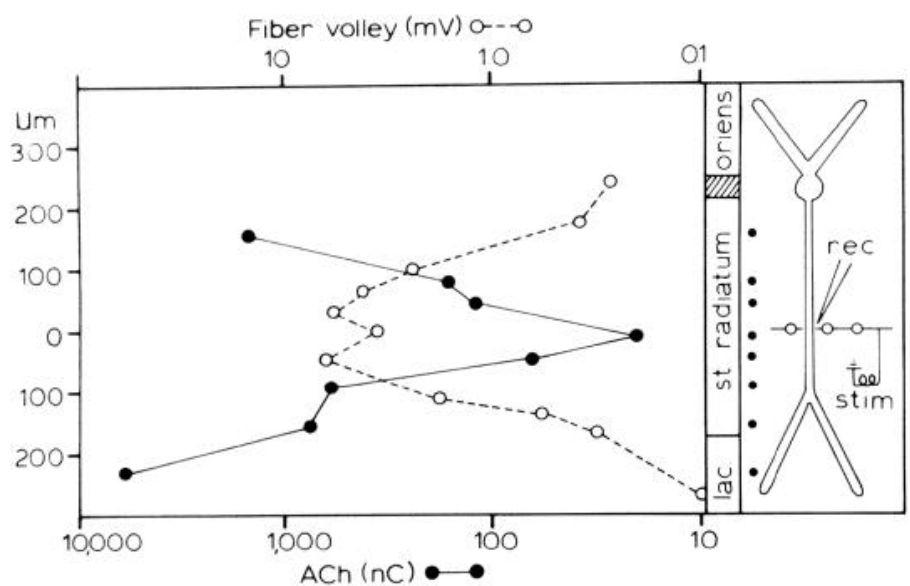

Figure 2. Similar distribution of ACh-sensitive sites and activated excitatory synapses in the CAl region. Schematic diagram of a CA1 pyramidal cell in the right panel indicates the position of stimulating ( $\mathrm{stim}$ ) and recording ( $\mathrm{rec}$ ) electrodes in the st. radiatum. The small black circles in the schematic indicate the eight sites in which $\mathrm{ACh}$ was ionophoresed. The distance of each site from the recording electrode is indicated in micrometers on the left ordinate. The solid circles in the graph refer to the bottom abscissa and represent the dose of $\mathrm{ACh}$, in nanocoulombs $(n C)$, necessary to reduce a control EPSP by $30 \%$ at each application site. The open circles in the graph refer to the top abscissa and indicate the size of the afferent fiber volley as the recording electrode was moved in a line parallel to the pyramidal cell axis. The abbreviation used is: lac, st. lacunosum moleculare.

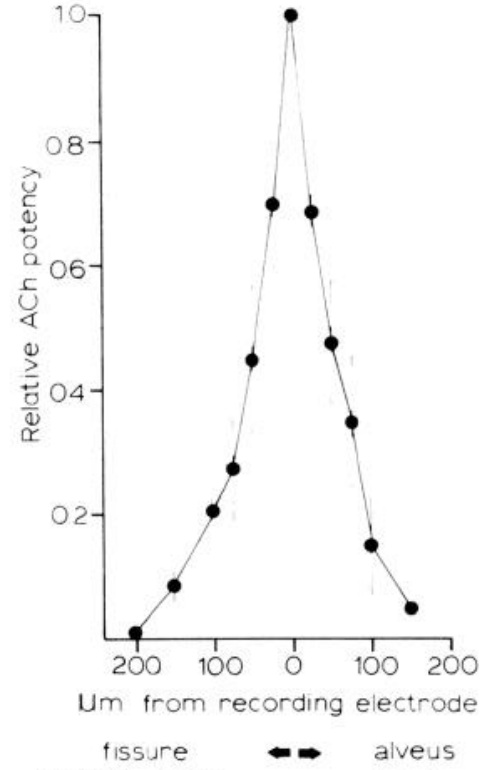

Figure 3. Rapid fall in ACh potency with increasing distance from activated synapses. ACh-sensitive sites were mapped out for eight slices as in Figure 2. At each of 12 standard intervals of distance from the recording electrode, the ACh potency, relative to its maximum potency at the recording site $(0 \mu \mathrm{m}$ on abscissa), was determined by interpolation from plots for individual slices. Each point indicates the mean relative potency of $\mathrm{ACh}$ at each site for eight slices. Vertical lines indicate \pm 1 SEM.

different recording sites. As expected, the volley amplitude decreased rapidly as the recording electrode was moved away from the stimulating electrode (Fig. 2, open circles). Although it is recognized that volume conduction of the signal away from the activated fibers will contribute somewhat to the measured volley amplitude, it has been demonstrated that a major proportion of the volley amplitude reflects the intensity of local afferent input (Andersen et al., 1978). The close correspondence between the distribution of $\mathrm{ACh}$-sensitive sites and the area of activated dendritic synapses (Fig. 2) was obtained in each of four slices tested.

The results from eight mapping experiments were pooled in order to illustrate the steepness with which the ACh potency falls off as the ionophoretic pipette is moved away from the most sensitive site (Fig. 3). Distances on the abscissa are expressed relative to the position of the recording electrode which, along with the stimulating electrode, was always positioned in the mid-apical dendritic layer of the CA1 region. In each slice, the ACh sensitivity was mapped out as in Figure 2; graphical interpolation then was used to determine the dose of ACh (in nanocoulombs) required for a criterion effect at standard intervals of 25 or $50 \mu \mathrm{m}$. The reciprocal of the $\mathrm{ACh}$ dose was expressed relative to that at the most sensitive site and was plotted as a function of distance from the recording electrode. The location of the $\mathrm{ACh}$ effect appears to be quite specific as moving the ionophoretic pipette $50 \mu \mathrm{m}$ in either direction decreased the relative potency of $\mathrm{ACh}$ by about $50 \%$ (Fig. 3).

Effect of ACh on intracellularly recorded EPSPs. Satisfactory intracellular recordings were obtained from 
38 pyramidal neurons. Although the resting properties of these cells varied somewhat during the course of the experiment, the mean membrane potential was $-65 \pm 3$ $\mathrm{mV}$ (range, 36 to $88 ; n=24$ ), input resistance was $32 \pm$ 2 megohms (range, 14 to $50 ; n=24$ ), and the action potential was $98 \pm 2 \mathrm{mV}$ (range, 80 to $128 ; n=35$ ).

Ionophoresis of $\mathrm{ACh}$ into the apical dendritic zone of pyramidal cells in the CA1 region of the slice decreased the peak of the intracellularly recorded EPSP by $46 \pm$ $3 \%$ ( $n=27$ cells). Figure $4 A$ illustrates the inhibitory effect of $\mathrm{ACh}$ on the evoked EPSP of a cell and the recovery following application. The input resistance of this cell, as indicated by the slope of the current-voltage plot in Figure $4 B$, was reduced by $6 \%$ in the presence of $\mathrm{ACh}$. However, both increases and decreases in input resistance resulted from ionophoresis of $\mathrm{ACh}$ in the st. radiatum. These changes were small, ranging from -10 to $6 \%$ (mean $=-2 \pm 1 \% ; n=12$ ), and did not correspond to the degree of inhibition of the EPSP produced by $\mathrm{ACh}$. The mean decrease in the EPSP produced by $\mathrm{ACh}$ in these 12 cells was $47 \pm 7 \%$. The changes in the membrane potential following dendritic $\mathrm{ACh}$ application usually developed slowly compared to the rapid reduction of the EPSP and ranged from 0 to $2 \mathrm{mV}$ depolarization (mean $=1.5 \mathrm{mV} ; n=16$ ). Thus, a profound reduction of the intracellularly recorded EPSP could be produced by dendritic application of $\mathrm{ACh}$ in the absence of consistent changes in either membrane potential or input resistance of pyramidal neurons.

Effect of ACh on intracellularly recorded IPSPs. Out of 11 slices in which lesions were made to isolate a pure recurrent IPSP, 9 showed no evidence of contamination by orthodromic EPSPs. The apparent reversal potential for recurrent IPSPs is so close to the resting potential that we usually evoked the IPSP at the plateau of a hyperpolarizing current pulse, which inverted the potential and increased its size (Fig. 5, top panel). Ionophoresis

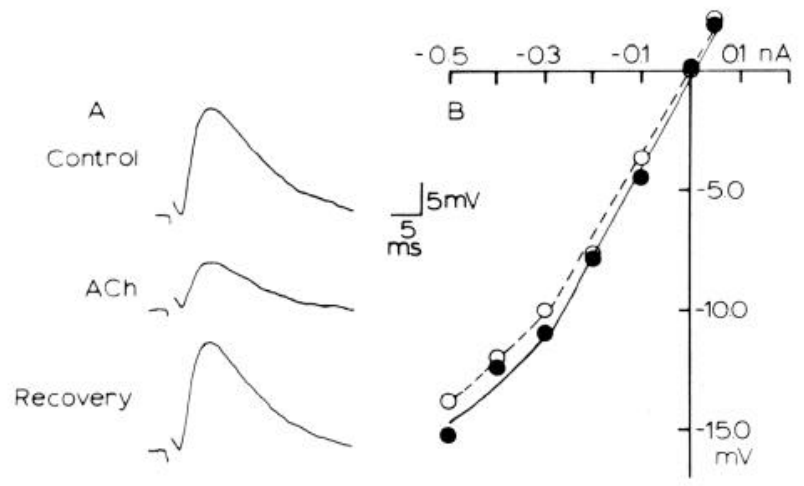

Figure 4. Depression by $\mathrm{ACh}$ of intracellularly recorded EPSPs. $A$, an EPSP recorded from a pyramidal cell in the CA1 region before (Control), 2 to $6 \mathrm{sec}$ after $(A C h)$, and following recovery from an ionophoretic dose of $\mathrm{ACh}(100 \mathrm{nA}$ for $8 \mathrm{sec})$ delivered into the st. radiatum. Each trace is the average of four sweeps. B, Current-voltage plot for the same cell. Solid circles were determined prior to $\mathrm{ACh}$ application, while open circles were determined $10 \mathrm{sec}$ after the start of the ACh application. Each pair of points was obtained from a separate $\mathrm{ACh}$ application. Input slope resistance was 37 megohms in control and 35 megohms in ACh.

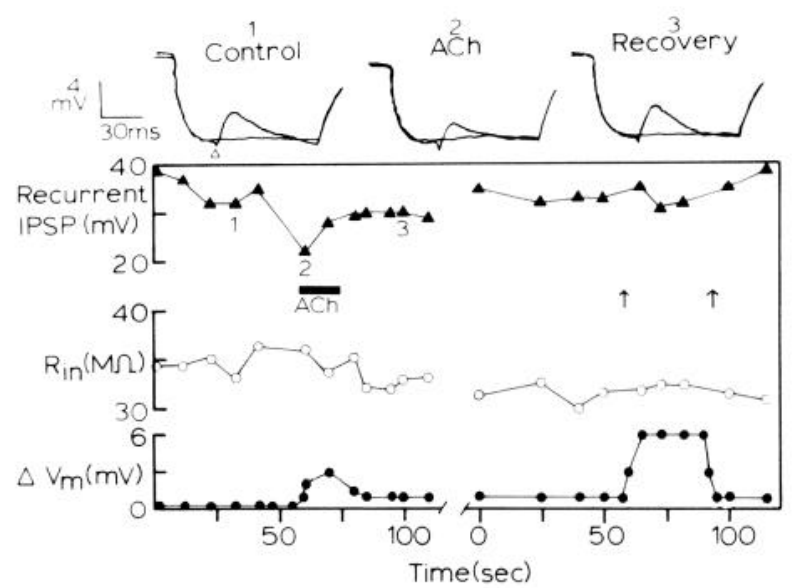

Figure 5. Depression by ACh of recurrent IPSPs. The sample records at the top of the figure illustrate a depolarizing recurrent IPSP evoked by alveus stimulation during a hyperpolarizing pulse prior to (1), $3 \mathrm{sec}$ after (2), and $52 \mathrm{sec}$ after (3) the start of a 15-sec application of ACh, $100 \mathrm{nA}$, into the cell layer. The small open triangle below trace 1 denotes the stimulus artifact. The bottom panel shows the time course of the changes in the IPSP, input resistance $\left(R_{\text {in }}\right)$ and membrane potential $\left(V_{m}\right)$ produced by, first, ionophoresis of $\mathrm{ACh}$ into the cell layer (left) and, second, by depolarization of the cell through direct current injection (right). The arrows indicate the time during which depolarizing steady current was applied. The break in the abscissa lasts 120 sec.

of $\mathrm{ACh}$ into st. pyramidale of these slices produced a transient, reversible decrease in the size of the recurrent IPSP in seven of nine cells. In another cell, the IPSP was decreased by $\mathrm{ACh}$, but recovery did not occur, and in the last cell, no change in the size of the IPSP was apparent after ionophoresis of $\mathrm{ACh}$ into the soma region. The inhibition of the IPSP and the time course of this effect in one cell are illustrated in Figure 5. The decrease in the IPSP usually occurred with little change in input resistance of the cell (Fig. 5). In nine effective perisomatic applications of $\mathrm{ACh}$ to seven cells, changes in input resistance were small at a time when the IPSP was depressed (range, -3 to 6 megohms; mean $=0.5 \pm 0.8$ megohms). In confirmation of previous work (Kelly et al., 1979; Benardo and Prince, 1980; Dodd et al., 1981), ionophoresis of $\mathrm{ACh}$ into st. pyramidale consistently depolarized pyramidal neurons by a mean of $6 \pm 1 \mathrm{mV}$ $(n=9)$. However, the depolarization was not solely responsible for the reduction of the IPSP, as shown in Figure 5, since a larger depolarization produced by passing steady current through the recording electrode resulted in only the expected small decrease in size of the IPSP as the synaptic driving force was reduced (period of current injection denoted by arrows). That the depolarization produced by $\mathrm{ACh}$ was not responsible for the inhibition of the recurrent IPSP also is suggested by the observation that the time courses of the two effects do not correspond (Fig. 5).

While application of ACh into st. pyramidale decreased the recurrent IPSP, the size and duration of evoked EPSPs were increased by ACh (Fig. 6). This is in contrast to the inhibition of the EPSP produced by application of $\mathrm{ACh}$ into the st. radiatum (Fig. 6) and is likely a result of inhibition of feed-forward and recurrent IPSPs. 


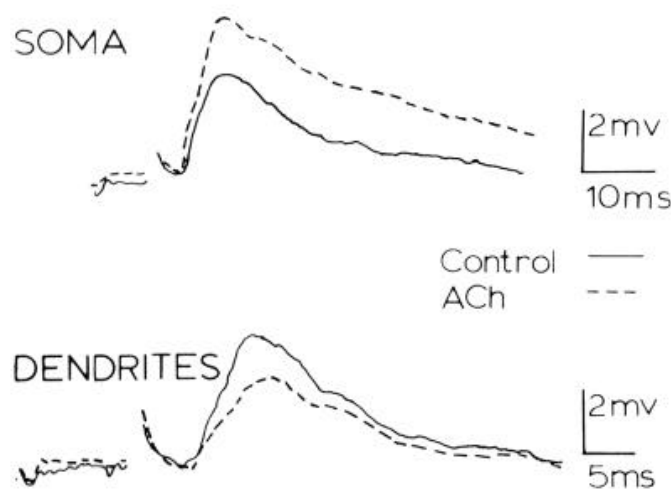

Figure 6. Reciprocal effect on EPSP of dendritic versus somatic application of $\mathrm{ACh}$. The top traces show an intracellularly recorded EPSP $20 \mathrm{sec}$ before (solid line) and $20 \mathrm{sec}$ after (dashed line) a 6-sec application of $\mathrm{ACh}, 100 \mathrm{nA}$, into the cell layer. The bottom traces show the EPSP in the same cell recorded $30 \mathrm{sec}$ before (solid line) and $8 \mathrm{sec}$ after (dashed line) a 13-sec application of ACh into the apical dendritic zone. Each trace is the average of four sweeps.

Presynaptic or remote dendritic inhibition by ACh? The observed inhibition by ACh of dendritically generated EPSPs could be effected by a reduction of excitatory transmitter release or, alternatively, by an increase in dendritic membrane conductance not detectable with an intrasomatic electrode but intense enough to shunt EPSP currents. The latter mechanism, which is termed remote dendritic inhibition (Frank, 1959), predicts that ACh should reduce similar depolarizations produced by ionophoresis of glutamate into the apical dendritic regions and also that the falling phase of the ACh-inhibited EPSP should be faster than normal. Both of these predictions were examined and found not to hold.

For the first test of remote dendritic inhibition, glutamate and ACh pipettes were positioned near to each other in st. radiatum, in the zone of orthodromically activated synapses. Pulses of glutamate, 30 to $140 \mathrm{msec}$ long (18 to $100 \mathrm{nA}$ ), were alternated with orthodromic stimulation and a hyperpolarizing current pulse so that glutamate was applied every 2 sec. ACh was ionophoresed after a control period of recording EPSPs, glutamate depolarizations, and hyperpolarizing pulses. In Figure 7, $A$ and $B$ demonstrate the effect of ACh on the EPSP $(A)$ and glutamate depolarization $(B)$ of one pyramidal neuron. ACh produced a $39 \%$ decrease in the recorded EPSP which was followed by complete recovery shortly after the ACh current was terminated (Fig. 7A). In contrast, the glutamate-induced depolarization remained nearly unchanged throughout the ACh application and following this period. The timing of the glutamate pulses is denoted by solid circles in the membrane potential record of Figure $7 \mathrm{~B}$. Likewise, the input resistance of the cell, as assessed by hyperpolarizing current pulses (Fig. 7B, up arrow), was unaffected by ACh. The interaction between dendritic applications of $\mathrm{ACh}$ and glutamate is summarized for seven cells in Figure $7 C$. Here, the response of each cell to dendritic glutamate pulses (at $0.5 \mathrm{~Hz}$ ) is represented by a solid line, and the period of $\mathrm{ACh}$ application, which varied from 6 to $18 \mathrm{sec}$ in different cells is indicated by symbols. ACh application started at time zero. Although the glutamate depolarization varied somewhat over the course of each experiment, it can be seen that ionophoresis of ACh did not produce a consistent change in the size of the glutamate response. In one cell, the glutamate effect appeared to be decreased when ACh was applied, however recovery of the response did not occur after the ACh current was off. In these seven cells, the EPSP was decreased by a mean of $39 \%$ during or immediately following ACh application, and this was followed by partial or full recovery in each case. Thus, the EPSP is inhibited dramatically by ACh at a time when input resistance and the depolarizing response to dendritic glutamate application are both unaffected. These results do not support a postsynaptic mechanism for the ACh effect.

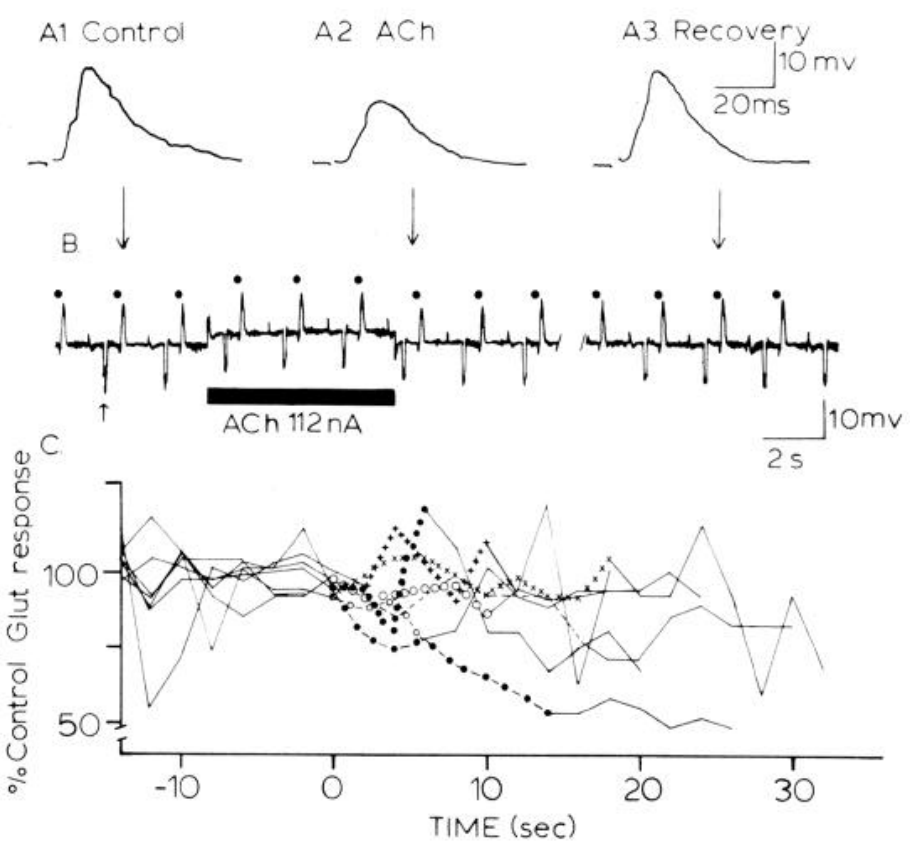

Figure 7. Effect of ACh on depolarizations evoked by short dendritic applications of glutamate to pyramidal cells. Ionophoretic pulses of glutamate $(100 \mathrm{nA}$ for $80 \mathrm{msec})$ applied into the apical dendritic zone were alternated with an orthodromic stimulus and a $-0.33 \mathrm{nA}$ hyperpolarizing transmembrane current pulse. $A$, Intracellularly recorded EPSP 4 sec before (1), 8 sec after (2), and $25 \mathrm{sec}$ after (3) the start of a 6-sec application of $\mathrm{ACh}, 112 \mathrm{nA}$, into the st. radiatum. Each trace is the average of two sweeps. $B$, Chart recording of the membrane potential of the same cell recorded before, during, and after application of ACh. Solid circles indicate the start of the glutamate pulse. The small up arrow indicates a hyperpolarizing pulse that was used to monitor input resistance. The records in $A$ were taken at the times indicated by the arrows pointing to the chart record in $B$. ACh application is denoted by the solid bar. The break in the record lasts $10 \mathrm{sec}$. $C$, Time course of the glutamate depolarization for seven cells. Each line represents results from a different cell. The ordinate indicates the percentage of the mean glutamate depolarization that was determined for seven glutamate (Glut) applications prior to the onset of the ACh dose at time 0 . The solid line before time 0 represents the percentage of the control glutamate response prior to $\mathrm{ACh}$ ionophoresis. The symbols represent the glutamate responses for seven individual cells during $\mathrm{ACh}$ application. The solid lines following the symbols represent glutamate reponses determined after the ACh current was turned off. 


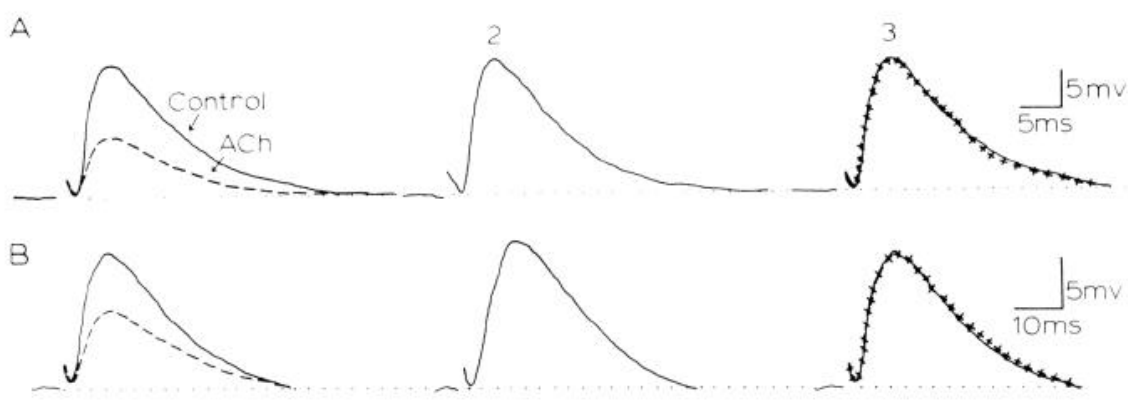

Figure 8. Effect of dendritically applied $\mathrm{ACh}$ on the time course of the intracellularly recorded EPSP in two cells $(A$ and $B)$. 1, An EPSP before (solid line) and after (dashed line) application of ACh to the dendritic tree. 2, Recovery of the EPSP following ACh application. 3, The EPSPs recorded in 1 were normalized so that the peak heights were the same. The solid line represents the control EPSP while $\times$ s represent the EPSP recorded during $\mathrm{ACh}$ application. Each trace is the average of four sweeps.

While an effort was made to position glutamate and ACh pipettes near each other, it might be argued that the patches of membrane activated synaptically and by glutamate ionophoresis were not always equidistant from the tip of the ACh barrel. If this were indeed the case, a local conductance increase caused by ACh could well affect the EPSP and glutamate response differentially. The second prediction of the remote dendritic inhibition hypothesis, that the time course of the ACh-inhibited EPSP should be altered, does not suffer from such geometrical constraints and is considered to be an especially sensitive test (Burke and Rudomin, 1977). This prediction was evaluated by comparing the shape of the EPSP in the presence and absence of ACh. Results from two cells are illustrated in Figure 8. The traces in Figure 8, $A 1$ and $B 1$, show control EPSPs (solid lines) and EPSPs recorded during dendritic application of $\mathrm{ACh}$ (dashed line); column two shows recovery for both cells. In column 3, the ACh-inhibited EPSP has been normalized algebraically so that its peak amplitude is the same as that of the control EPSP. Using this normalization procedure, it can be seen that a large reduction in the peak height of the EPSP is not accompanied by a faster time course of either the rising or falling phases of the EPSP. This result is consistent with the idea that $\mathrm{ACh}$ decreases the size of the EPSP by reducing the amount of transmitter released. Similar results were obtained in six cells whose time course was examined in detail.

For two of these cells, $10^{-5} \mathrm{M}$ bicuculline methiodide had been added to the perfusing fluid in an attempt to eliminate the IPSP component of the orthodromic response. In these cells, strong orthodromic stimulation evoked intense burst responses indicative of reduced synaptic inhibition (Wong and Prince, 1979; Dingledine and Gjerstad, 1979, 1980). However, the EPSP evoked by weaker stimulation did not decay passively, suggesting that nonlinearities in the dendritic membrane or perhaps a non-GABA ( $\gamma$-aminobutyric acid) IPSP contributed to the falling phase of the EPSP. In these two cells, as in the others tested, ACh did not alter the rate of decay of the EPSP.

An experiment, carried out using an analog model of a dendritic neuron with an electrotonic structure similar to that reported for hippocampal pyramidal neurons, con- firmed that a dendritic conductance increase sufficient to reduce the peak of a local "EPSP" by $40 \%$ both shortened the time-to-peak and dramatically quickened the falling phase of the potential (not shown).

\section{Discussion}

Previous ionophoretic studies of the action of $\mathrm{ACh}$ in the hippocampus have emphasized a slow, presumably direct excitatory effect of muscarinic agonists on pyramidal and granule cells, an action later shown to be due to depolarization and conductance decrease (Kelly et al., 1979; Benardo and Prince, 1980; Dodd et al., 1981). We found that the depolarizing action of ACh was more prominent during perisomatic, rather than dendritic, application of the drug. This finding suggests that the receptors mediating the depolarizing effect of $\mathrm{ACh}$ are located on or near the pyramidal cell body. The present study demonstrates that, in addition to this slow, depolarizing effect, ACh exerts a rapid, powerful, muscarinic inhibitory effect upon both excitatory and inhibitory afferents to CA1 pyramidal neurons. Several lines of evidence lead us to conclude that this effect of ACh is not a form of remote postsynaptic inhibition but rather is mediated by a decrease in the amount of transmitter released per afferent volley. Dendritically applied ACh reduced the peak height of locally evoked EPSPs without decreasing their rise or or fall time and without changing membrane potential or input resistance. In addition, ACh had little or no effect upon dendritic depolarizations evoked by short pulses of glutamate. Finally, ACh reduced dendritic postsynaptic current density in field potential recordings, and this inhibitory effect was limited spatially to the zone of activated synapses. The remaining alternative, that $\mathrm{ACh}$ might interfere with postsynaptic receptor activation, appears unlikely in view of our observation that spatially separate EPSPs and IPSPs, which are mediated by different neurotransmitters, could be reduced in the same cells by appropriately placed ACh applications. Thus, our work provides firm evidence for the postulate of presynaptic cholinergic inhibition made by Yamamoto and Kawai (1972) and Hounsgaard (1978a, b) and is in accord with the recent observations of Reiffenstein et al. (1980) in the intact rat hippocampus. 
The cellular mechanism for the presynaptic inhibitory effect of ACh in the hippocampus is uncertain. ACh may produce excessive depolarization of afferent nerve terminals, thus decreasing the safety factor for spike invasion. This postulate is tempting as it allows a decrease in potassium conductance to account for both postsynaptic excitatory and presynaptic inhibitory actions of ACh in the hippocampus. However, the rapid presynaptic inhibitory effects of $\mathrm{ACh}$ were dissociated temporally from the slow, direct depolarizing action, and a change in the shape or size of the compound presynaptic action potential that one might predict for this mechanism (Sypert et al., 1980) was not apparent. In this regard, it is important to ask whether measurement of the "presynaptic volley" (Fig. 1) is dominated by activity in throughgoing axons or whether it accurately reflects depolarization at transmitter release sites. Ultrastructural studies of serial sections through st. radiatum in CA1 indicate that beaded or varicose swellings, which contain synaptic vesicles, arise at intervals along the thin, unmyelinated axons of this region (Westrum and Blackstad, 1962). Preterminal branching was not reported. In this situation, one would expect that changes in presynaptic terminal depolarization would be signaled faithfully by the extracellularly recorded fiber volley since the transmitter release sites should be electrotonically close to the parent axon. On the other hand, there is no direct evidence that such varicosities possess muscarinic receptors, and it is possible that a proportion of presynaptic terminals arises from thin branches of the parent axon. Given these uncertainties, the interpretation of drug effects on the fiber volley should be made with caution. Hounsgaard (1978a, b) provided evidence for a small increase in afferent fiber excitability during dendritic applications of $\mathrm{ACh}$, although the temporal relationship of this effect to presynaptic inhibition and the possibility that it resulted from a separate depolarizing effect of ACh were not examined. An alternative mechanism for decreasing release of neurotransmitter involves interference with stimulus-secretion coupling in the nerve terminal. This could be accomplished by blocking a voltage-sensitive inward calcium current in a manner similar to that shown in Aplysia by Wilson and Wachtel (1978). Indeed, the effect of ACh on the synaptic transfer curve (Fig. 1) appears to be virtually identical to that of simply reducing the bath calcium concentration (Dingledine and Somjen, 1981). Recent studies indicate that a similar mechanism may cause a reduction in transmitter release by opiates at sensory nerve terminals (Mudge et al., 1979) and by adrenergic agonists at sympathetic ganglia (Minota and Koketsu, 1977).

Although most of our observations were made in the CA1 region, the presynaptic inhibitory action of $\mathrm{ACh}$ is quite widespread within the hippocampal formation, occurring in CA3 and fascia dentata as well as the three major strata in CA1. Szerb et al. (1977) have provided evidence for autoreceptors on cholinergic inputs to the hippocampus. From our work, it appears that a large proportion of noncholinergic inputs to pyramidal and granule cells also may be under inhibitory cholinergic control. The dispersed pattern of septal terminations within the hippocampal formation is in accord with this suggestion. Although axoaxonic synapses, which are considered to mediate at least part of classical presynaptic inhibition in the spinal cord (Gray, 1962), have not been reported in hippocampus (Blackstad, 1963; Gottlieb and Cowan, 1972), it is possible that diffusion of transmitter from cholinergic synapses could influence nearby terminals. The pharmacological demonstration of presynaptic inhibitory effects of ACh should be taken into account when considering the possible physiological involvement of the septohippocampal pathway in such phenomena as $\theta$ rhythm (Stumpf, 1965; Andersen et al., 1979) and its associated behaviors. On the other hand, convincing physiological evidence for neurally mediated presynaptic inhibition in the hippocampus is lacking. Our efforts to demonstrate direct effects of muscarinic antagonists and cholinesterase inhibitors on synaptic transmission in the slice have failed so far (R. J. Valentino and R. Dingledine, unpublished), and there are few reports in the literature suggestive of a presynaptic inhibitory role for septal afferents. Further evaluation of this hypothesis will depend on the results of in vivo studies designed specifically to search for possible interactions between septal and intrahippocampal afferents, along the lines of the paper by Alvarez-Leefmans and Gardner-Medwin (1975).

\section{References}

Alvarez-Leefmans, F. J., and A. R. Gardner-Medwin (1975) Influences of the septum on the hippocampal dentate area which are unaccompanied by field potentials. J. Physiol. (Lond.) 249: 14-16P.

Andersen, P., H. Bruland, and B. R. Kaada (1961a) Activation of the dentate area by septal stimulation. Acta Physiol. Scand. 51: 17-28.

Andersen, P., H. Bruland, and B. R. Kaada (1961b) Activation of field CA1 of the hippocampus by septal stimulation. Acta Physiol. Scand. 51: 29-40.

Andersen, P., H. Silfvenius, S. H. Sundberg, O. Sveen, and H. Wigström (1978) Functional characteristics of unmyelinated fibers in the hippocampal cortex. Brain Res. 144: 11-18.

Andersen, P., H. B. Bland, T. Myher, and P. A. Schwartzkroin (1979) Septo-hippocampal pathway necessary for dentate theta production. Brain Res. 165: 13-22.

Benardo, L. S., and D. A. Prince (1980) Acetylcholine: A neuromodulator of hippocampal pyramidal neurons. Soc. Neurosci. Abstr. 6: 514.

Bird, S. J., and G. K. Aghajanian (1975) Denervation supersensitivity in the cholinergic septo-hippocampal pathway: A microiontophoretic study. Brain Res. 100: 355-370.

Biscoe, T. J., and D. W. Straughan (1966) Micro-electrophoretic studies of neurones in the cat hippocampus. J. Physiol. (Lond.) 183: 341-359.

Blackstad, T. W. (1963) Ultrastructural studies on the hippocampal region. Prog. Brain Res. 3: 122-148.

Bland, B. H., G. K. Kostopoulos, and J. W. Phillis (1974) Acetylcholine sensitivity of hippocampal formation neurons. Can. J. Physiol. Pharmacol. 52: 966-971.

Burke, R. E., and P. Rudomin (1977) Spinal neurons and synapses. In Handbook of Physiology. Section 1: The Ner. vous System, E. R. Kandel, ed., Vol. I, pp. 877-944, The American Physiological Society, Bethesda, MD.

DeFrance, J. F., J. C. Stanley, J. E. Marchand, and R. B. Chronister (1978) Cholinergic mechanisms and short-term potentiation. In Functions of the Septo-Hippocampal System: Ciba Foundation Symposium 58, pp. 109-122, ElsevierNorth Holland, New York. 
Dingledine, R., and L. Gjerstad (1979) Penicillin blocks hippocampal IPSPs, unmasking prolonged EPSPs. Brain Res. 168: 205-209.

Dingledine, R., and L. Gjerstad (1980) Reduced inhibition during epileptiform activity in the in vitro hippocampal slice. J. Physiol. (Lond.) 305: 297-313.

Dingledine, R., and I. A. Langmoen (1980) Conductance changes and inhibitory actions of hippocampal recurrent IPSPs. Brain Res. 185: 277-287.

Dingledine, R., and G. Somjen (1981) Calcium dependence of synaptic transmission in the hippocampal slice. Brain Res. 207: 218-222.

Dingledine, R., J. Dodd, and J. S. Kelly (1980) The in vitro brain slice as a useful neurophysiological preparation for intracellular recording. J. Neurosci. Meth. 2: 323-362.

Dodd, J., R. Dingledine, and J. S. Kelly (1981) The excitatory action of acetylcholine on hippocampal neurones of the guinea pig and rat maintained in vitro. Brain Res. 207: 109127.

Dudar, J. D. (1975) The effect of septal nuclei stimulation on the release of acetylcholine from the rabbit hippocampus. Brain Res. 83: 123-133.

Engel, E., V. Barcilon, and R. S. Eisenburg (1972) The interpretation of current-voltage relations recorded from a spherical cell with a single microelectrode. Biophys. J. 12: 384-403.

Frank, K. (1959) Basic mechanisms of synaptic transmission in the central nervous system. I.R.E. Trans. Electr. $M E-6: 85-$ 88.

Gottlieh, D. I., and W. M. Cowan (1972) On the distribution of axonal terminals containing spheroidal and flattened synaptic vesicles in the hippocampus and dentate gyrus of the rat and cat. Z. Zellforsch. Mikrosk. Anat. 129: 413-419.

Gray, E. G. (1962) A morphological basis for presynaptic inhibition? Nature 193: 82-83.

Hounsgaard, J. (1978a) Inhibition produced by iontophoretically applied acetylcholine in area CAl of thin hippocampal slices from the rat. Acta Physiol. Scand. 103: 110-111.

Hounsgaard, J. (1978b) Presynaptic inhibitory action of acetylcholine in area CA1 of the hippocampus. Exp. Neurol. 62: 787-797.

Kelly, J. S., J. Dodd, and R. Dingledine (1979) Acetylcholine as an excitatory and inhibitory transmitter in the mammalian central nervous system. Prog. Brain Res. 49: 253-266.

Lewis, P. R., C. C. D. Shute, and A. Silver (1967) Confirmation from choline acetylase of a massive cholinergic innervation to the rat hippocampus. J. Physiol. (Lond.) 191: 215-224.

Lorente de Nó, R. (1931) Studies on the structure of the cerebral cortex. II. Continuation of the study on the ammonic system. J. Psychol. Neurol. (Lpz.) 46: 113-177.

Mellgren, S. I., and B. Srebro (1973) Changes in acetylcholinesterase and distribution of degenerating fibers in the hippocampal region after septal lesions in the rat. Brain Res. 52: 19-36.

Minota, S., and K. Koketsu (1977) Effects of adrenaline on the action potential of sympathetic ganglion cells in bullfrogs. Jpn. J. Physiol. 27: 353-366.

Mosco, S., G. Lynch, and C. Cotman (1973) The distribution of septal projections to the hippocampus of the rat. J. Comp. Neurol. 152: 163-174.

Mudge, A., S. Leeman, and G. D. Fishbach (1979) Enkephalin inhibits release of substance $P$ from sensory neurons in culture and decreases action potential duration. Proc. Natl. Acad. Sci. U. S. A. 76: 526-530.

Reiffenstein, R. J., K. Krnjević, and N. Ropert (1980) Acetylcholine has a powerful disinhibitory action in the hippocampus. Soc. Neurosci. Abstr. 6: 514.

Rose, A. M., T. Hattori, and H. C. Fibiger (1976) Analysis of the septo-hippocampal pathway by light and electron microscopic autoradiography. Brain Res. 108: 170-174.

Salmoiraghi, G. C., and C. N. Stefanis (1967) A critique of iontophoretic studies of central nervous system neurons. Int. Rev. Neurobiol. 10: 1-30.

Segal, M. (1978) The acetylcholine receptor in the rat hippocampus: Nicotinic, muscarinic or both? Neuropharmacology 17: 619-623.

Segal, M., and S. Landis (1974) Afferents to the hippocampus of the rat studied with the method of retrograde transport of horseradiash peroxidase. Brain Res. 78: 1-15.

Stumpf, C. (1965) Drug action on the electrical activity of the hippocampus. Int. Rev. Neurobiol. 8: 77-138.

Swanson, L. W. (1978) The anatonical organization of septohippocampal projections. In Functions of the Septo-Hippocampal System: Ciba Foundation Symposium 58, pp. 25-43, Elsevier-North Holland, New York.

Sypert, G. W., J. B. Munson, and J. W. Fleshman (1980) Effect of presynaptic inhibition on axonal potentials, terminal potentials, focal synaptic potentials, and EPSPs in cat spinal cord. J. Neurophysiol. 44: 792-803.

Szerb, J. C., P. Hadhazy, and J. D. Dudar (1977) Release of $\left[{ }^{3} \mathrm{H}\right]$-acetylcholine from rat hippocampal slices: Effect of septal lesion and of graded concentrations of muscarinic agonists and antagonists. Brain Res. 128: 285-291.

Valentino, R. J., and R. Dingledine (1981) Acetylcholine inhibits synaptic transmission in the rat hippocampal slice. Fed. Proc. 40: 321.

Westrum, L. E., and T. W. Blackstad (1962) An electron microscopic study of the stratum radiatum of the rat hippocampus (regio superior, CA1) with particular emphasis on synaptology. J. Comp. Neurol. 119: 281-309.

Wilson, W. A., and H. Wachtel (1978) Prolonged inhibition in burst-firing neurons: Synaptic inactivation of the slow regenerative inward current. Science 202: 772-775.

Wong, R. K. S., and D. A. Prince (1979) Dendritic mechanisms underlying penicillin-induced epileptiform activity. Science 204: 1228-1231.

Yamamoto, C., and N. Kawai (1967) Presynaptic action of acetylcholine in thin sections from the guinea pig dentate gyrus in vitro. Exp. Neurol. 19: 176-187. 